Article

\title{
Secretory Laccase from Pestalotiopsis Species CDBT-F-G1 Fungal Strain Isolated from High Altitude: Optimization of Its Production and Characterization
}

\author{
Mukesh Yadav ${ }^{1}$, Garima Bista ${ }^{1}$, Rocky Maharjan ${ }^{1}$, Pranita Poudyal ${ }^{1}$, Milan Mainali ${ }^{1}$, \\ Lakshmaiah Sreerama ${ }^{2, *}$ and Jarina Joshi ${ }^{1, *}$ \\ 1 Central Department of Biotechnology, Tribhuvan University, Kirtipur 44618, Nepal; \\ adhikarimukesh1991@gmail.com (M.Y.); garisharma000@gmail.com (G.B.); \\ rocky.maharjan@biotechtu.edu.np (R.M.); poudyalpranita@gmail.com (P.P.); \\ mainalimilan50@gmail.com (M.M.) \\ 2 Department of Chemistry and Earth Sciences, Qatar University, P. O. Box 2713, Doha, Qatar \\ * Correspondence: lsreerama@gmail.com (L.S.); jarinarjoshi@gmail.com (J.J.)
}

Received: 23 November 2018; Accepted: 13 December 2018; Published: 18 January 2019

\begin{abstract}
Microorganisms producing laccases may be used for the pretreatment of lignocellulosic biomass to recover fermentable sugar. Very few fungi and other microbes growing in high altitudes have been tested for this purpose. As part of this study, we have collected soil samples from different parts of the Kathmandu Valley and the Rautahat at district of Nepal (1600 to $2303 \mathrm{~m}$ above sea level) and successfully cultured 53 different isolates of microorganisms. Among the 53 isolates obtained 30 were Actinomycetes, 20 were Streptomycetes, and three were fungi). These isolates were tested for laccase expression using guaiacol, tannic acid, and 1-naphthol as substrates. Twelve of the 53 isolates tested positive for the expression of laccase. Among the laccase- positive isolates, a fungal species designated as CDBT-F-G1 was found to produce high levels of laccase. This isolate was identified as Pestalotiopsis species based on 18S rRNA sequencing. Pestalotiopsis spp. CDBT-F-G1 isolate grows efficiently in PDB media containing $1 \%$ Kraft lignin at pH 5 and $30{ }^{\circ} \mathrm{C}$ and secretes $20 \pm 2 \mathrm{U} / \mathrm{mL}$ laccase in culture medium. Further optimization of growth conditions revealed that addition of (i) metal salts, e.g., $1 \mathrm{mM}$ magnesium sulfate $(51 \pm 25 \mathrm{U} / \mathrm{mL}$ ); (ii) agitation of cultures at $200 \mathrm{rpm}$ (51 $\pm 9 \mathrm{U} / \mathrm{mL}$ ); (iii) surfactants, e.g., $0.75 \mathrm{mM}$ Tween 80 ( $54 \pm 14 \mathrm{U} / \mathrm{mL}$ ); (iv) 40\% dissolved $\mathrm{O}_{2}$ ( $57 \pm$ $2 \mathrm{U} / \mathrm{mL})$ and inducers, e.g., $1 \mathrm{mM}$ gallic acid $(69 \pm 11 \mathrm{U} / \mathrm{mL})$, further promote laccase production by Pestalotiopsis spp. CDBT-F-G1 isolate. On the other hand, $0.1 \mathrm{mM}$ cysteine inhibited laccase production. The secretory laccase obtained from fermentation broth of CDBT-F-G1 was partially purified by ammonium sulfate (13-fold purification with specific activity $26,200 \mathrm{U} / \mathrm{mg}$ ) and acetone (14-fold purification with specific activity $31,700 \mathrm{U} / \mathrm{mg}$ ) precipitation methods. The enzyme has an approximate molecular mass of $43 \mathrm{kDa}$, $\mathrm{pH}$ and temperature optima were $\mathrm{pH} 6$ and $60^{\circ} \mathrm{C}$, respectively. $\mathrm{V}_{\max }$ and $\mathrm{K}_{\mathrm{m}}$ were $100 \mu \mathrm{mol} / \mathrm{min}$ and $0.10 \mathrm{mM}$, respectively, with ABTS as the substrate. Given the above characteristics, we believe Pestalotiopsis spp. CDBT-F-G1 strain native to high altitudes of Nepal could be used to pretreat lignocellulosic biomass to efficiently recover fermentable sugars.
\end{abstract}

Keywords: laccase; lignin; Pestalotiopsis spp. CDBT-F-G1; guaiacol; tannic acid and 1 naphthol

\section{Introduction}

Laccases (benzenediol: oxygen oxidoreductase; EC 1.10.3.2) are multi-copper metallo-oxidases that catalyze one electron oxidation and reduce molecular oxygen to water. These enzymes exhibit 
broad substrate specificity, and operate in the $\mathrm{pH}$ range of $\mathrm{pH} 3-5$ and temperatures range from $40-60{ }^{\circ} \mathrm{C}$ [1]. Laccases are found in a variety of organisms, including bacteria, fungi, insects, higher plants, and animals. Laccases are secreted during secondary metabolism, especially under limited nutrient levels (mostly nitrogen sources) [2]. These enzymes are biotechnologically important due to their ability to oxidize both phenolic and non-phenolic lignin-related compounds [3] and highly recalcitrant environmental pollutants [4]. The type of degradation caused by laccases is expected to be very useful for the treatment of lignocellulosic biomass, waste water, and dye degradation [5]. Laccases are also increasingly being used in (i) the production of value-added chemicals from lignin; (ii) paper and pulp bleaching; (iii) prevention of wine discoloration; (iv) waste bleaching and detoxification; (v) bioremediation; and (vi) biosensors. Given the applications, laccases have been a subject of research since the 19th century and the search for potent laccases still continues [6].

Lignocellulosic biomass plays an important role in biofuel production as well as the paper and pulp industry. Effective degradation of lignocellulosic biomass has been a subject of research, especially in the area of biofuels production, for a long time, because it is the limiting factor in recovery of fermentable sugars from lignocellulosic biomass. Among the lignin-modifying enzymes, laccases constitute a major group of enzymes responsible for delignification. Genetic manipulation of plants to reduce lignin content in plants, which would lead to improved sugar yields from lignocellulose and, thus, increased ethanol production, has also been reported. Such genetic manipulations have also shown that lignin reduction below a certain threshold can cause large changes in wood chemistry and plant metabolism, ultimately resulting in low ethanol yields [7]. Given the above, the use of laccase(s) to effectively pretreat lignocellulosic biomass appears to be more efficient in recovering fermentable sugars. The latter necessitates finding novel laccase with higher stability and optimal enzyme activity for industrial application. However, a serious problem often encountered in industrial exploitation of laccases reported so far is that their secretion into the broth by microorganisms are low/limited. Therefore, it is important to identify organisms, especially fungi that secrete high levels of laccases. With the latter as a goal, reported herein is the screening and identification of a fungus that can produce significantly higher levels of extracellular laccase with desirable properties.

\section{Materials and Methods}

\subsection{Materials}

ABTS (2,2'-azino-bis (3-ethylbenzothiazoline-6-sulfonicacid), Kraft lignin, guaiacol, tannic acid, gallic acid, and 1 naphthol were purchased from Hi-Media Pvt. Ltd., New Delhi, India. Protein molecular weight markers were purchased from Genei Pvt. Ltd., Bangalore, India. All other chemicals were of analytical grade and were purchased locally.

\subsection{Sample Collection}

Soil samples (eight), mushroom culture, and dry mushroom were used for the isolation of microbes. The soil samples were collected from different places of Kathmandu Valley (Kirtipur, Balkhu, Dhobighat, Gwarko, and Putalisadak) and three from the Rautahat district of Nepal (1600 to $2303 \mathrm{~m}$ above sea level). Mushroom cultures (whole body dried and PDA cultures) were obtained from the Nepal Academy of Science and Technology (NAST), Nepal. This was originally collected from Phulchoki Hill, Lalitpur (Kathmandu valley), Nepal. Additionally, thirty Actinomycetes spp., previously isolated and stored in the Central Department of Biotechnology, Kirtipur, Nepal, were also used for the screening of laccase activity. All the Actinomycetes spp. were isolated from soil samples collected from the Tribhuvan University campus, Kirtipur, Nepal. 


\subsection{Isolation, Screening, and Identification of Laccase-Producing Microbes}

\subsubsection{Isolation and Screening of Microbial Species for Laccase Production}

For isolation of microbes (Actinomycetes and fungi) from the soil samples, each of the collected soil samples were first serially diluted and the diluted samples were spread evenly over the surface of starch casein agar plates containing $50 \mu \mathrm{g} / \mathrm{mL}$ cycloheximidine to isolate Actinomycetes [8]. Further, the diluted samples along with the cut end of whole body of fungus were spread on PDA plates without cycloheximidine to isolate fungus. Plates were incubated at 37 and $28^{\circ} \mathrm{C}$, respectively, and monitored after 48,72 , and $96 \mathrm{~h}$. The colonies formed on the plates were sub-cultured in respective media. Pure isolates thus prepared were stored at $4{ }^{\circ} \mathrm{C}$ for further use. Streptomycetes species were sub-cultured using ISP-2 medium (Hi Media, New Delhi, India). Respective media supplemented with guaiacol $(0.02 \%$ in PDA) and tannic acid (0.5\% in PDA), and $5 \mathrm{mM}$ of 1-naphthol were used for screening laccase-producing microbes.

\subsubsection{Isolation of Genomic DNA (gDNA)}

High-quality gDNA was extracted from the laccase producing strain with the highest laccase activity as described previously [9]. Briefly, the fungal mycelia (tissues) were homogenized in $400 \mu \mathrm{L}$ of sterilized salt homogenizing buffer $(0.4 \mathrm{M} \mathrm{NaCl}, 10 \mathrm{mM}$ Tris- $\mathrm{HCl}$ of $\mathrm{pH} 8.0$ and $2 \mathrm{mM}$ EDTA of $\mathrm{pH} 8)$. The homogenates were then mixed with $2 \%$ sodium dodecyl sulfate (SDS) and $400 \mu \mathrm{g} / \mathrm{mL}$ proteinase $\mathrm{K}$ and incubated at $55-65^{\circ} \mathrm{C}$ overnight. At the end of overnight incubation, the samples were mixed with $300 \mu \mathrm{L}$ of $6 \mathrm{M} \mathrm{NaCl}$, vortexed for $30 \mathrm{~s}$, and centrifuged at $10,000 \times g$ for $30 \mathrm{~min}$. The supernatants were then transferred to fresh microfuge tubes, mixed with equal volumes of isopropanol and stored at $-20^{\circ} \mathrm{C}$ for $1 \mathrm{~h}$ to precipitate DNA. Finally, the samples were centrifuged at $4{ }^{\circ} \mathrm{C}$ at $10,000 \times g$ for $20 \mathrm{~min}$. The supernatants were poured off; the pellets were washed with $70 \%$ alcohol by rinsing and dried in a laminar airflow hood. The dried pellets were re-suspended in $500 \mu \mathrm{L} 50 \mathrm{mM}$ Tris-EDTA buffer supplemented with $1 \mu \mathrm{g} / \mathrm{mL}$ RNase and stored at $-20{ }^{\circ} \mathrm{C}$ until further use.

\subsubsection{PCR Amplification of $18 S$ rRNA and Sequencing}

The isolated gDNA was used as template in PCR to amplify $18 \mathrm{~S}$ rRNA genes. The forward and reverse primers used for this purpose were $5^{\prime}$ GGTCTTGTAATTGGAATGAG3' and 5'CTTCCGTCAATTCCTTTAAG3', respectively. PCR amplification was carried out as described by Dhanashekaran and associates, 2014 [10]. The PCR products were analyzed using 1\% agarose gels. The purified PCR products were sequenced commercially (Xcelris Labs Ltd., Ahmedabad, India).

\subsubsection{Optimization of Laccase Production}

The high yielding fungal species identified from the screening experiments were cultured in PDA medium containing $1 \% \mathrm{Kraft}$ lignin. The laccase production was optimized by varying (i) $\mathrm{pH}$ (ranging from $4-10$ with the interval of $1 \mathrm{pH}$ unit); (ii) Temperature (ranging from $20-50{ }^{\circ} \mathrm{C}$ with the interval of $5{ }^{\circ} \mathrm{C}$ ); (iii) agitation at 100, 150, and $200 \mathrm{rpm}$; (iv) dissolved oxygen (DO) at 35\%, 40\%, and 50\%, (v) inducers and inhibitors - vanillin, gallic acid, catechol, guaiacol, sodium azide, cysteine, and EDTA at concentrations of $0.1,1$, and $2 \mathrm{mM}$; (vi) metal salts- $\mathrm{MgSO}_{4}, \mathrm{ZnSO}_{4}, \mathrm{Fe}_{2}\left(\mathrm{SO}_{4}\right)_{3}$ and $\mathrm{CuSO}_{4}$ at 1 and $2 \mathrm{mM}$ concentration; and (vii) surfactants-tween 20 and tween 80 at $0.25,0.5,0.75$, and $1 \mathrm{mM}$ concentrations [11].

\subsection{Determination of Laccase Activity}

Laccase activity was measured at room temperature using $1 \mathrm{mM}$ ABTS as substrate prepared in $0.1 \mathrm{M}$ of sodium acetate buffer at $\mathrm{pH}$ 5. Reaction was carried out as described in Airong et al. [12], 2008 by observing absorbance at $420 \mathrm{~nm}$ after incubating ABTS with laccase enzyme at $37^{\circ} \mathrm{C}$. One unit of enzyme activity $(\mathrm{U})$ was defined $1 \mu \mathrm{mol}$ of substrate reduced $/ \mathrm{min}$ [12]. 


\subsection{Isolation and Partial Characterization of Laccase}

\subsubsection{Enrichment of Laccase}

Laccase secreted into the culture media was isolated and enriched by ammonium sulfate and acetone precipitation methods. For ammonium sulfate precipitation of laccase, $100 \mathrm{~mL}$ culture broth was cooled on ice bath, solid ammonium sulfate was added by slow mixing until its concentrations was $40 \%(w / v)$. The mixture was incubated for $2 \mathrm{~h}$ at $4{ }^{\circ} \mathrm{C}$ to allow protein precipitation. The mixture was centrifuged at $10,000 \times g$ for $15 \mathrm{~min}$. The precipitate was discarded, and supernatant was further mixed with ammonium sulfate to adjust concentration to $70 \%(w / v)$ and incubated overnight at $4{ }^{\circ} \mathrm{C}$ for complete precipitation. Acetone precipitates were prepared by mixing $100 \mathrm{~mL}$ filtered culture broth with 1:5 volume of cold acetone and incubated for $1 \mathrm{~h}$ at $-20{ }^{\circ} \mathrm{C}$. Each of the precipitates were centrifuged and dissolved in $10 \mathrm{~mL}$ of $0.1 \mathrm{M}$ sodium acetate buffer, $\mathrm{pH}$. The samples were dialyzed against the same buffer at $4{ }^{\circ} \mathrm{C}$ overnight and stored at $4{ }^{\circ} \mathrm{C}$ for further use $[13,14]$.

\subsubsection{Protein Concentration Determination}

Protein content in various preparations was determined using the Bradford method [15] with $10 \mu \mathrm{g} / \mathrm{mL}$ bovine serum albumin (BSA) as standard. The absorbance was measured at $595 \mathrm{~nm}$.

\subsubsection{SDS Gel Electrophoresis}

The molecular mass of laccase was determined using SDS-PAGE. Standard molecular weight markers obtained from Genei India Pvt. Ltd. (Karnataka, India), were used as reference markers. The proteins were visualized by staining the gels with Coommassie Brilliant Blue G250 (Bio-Rad Labs, Palo Alto, CA, USA) [16].

\subsubsection{Characterization of Laccase}

The optimum temperature and $\mathrm{pH}$ for partially purified laccase was determined by incubating the enzyme at temperatures ranging from 20 to $80^{\circ} \mathrm{C}$, and $\mathrm{pH}$ ranging from 1 to 11 . Temperature and pH stability of partially purified laccase enzyme were also determined by pre-incubating the laccase for $1 \mathrm{hr}$ at different temperatures (30 to $80^{\circ} \mathrm{C}$ ) and $\mathrm{pH}$ ( $\mathrm{pH} 2$ to 10). The Lineweaver-Burk plots were used to determine kinetic parameters $\left(\mathrm{K}_{\mathrm{m}}\right.$ and $\left.\mathrm{V}_{\max }\right)$ of the partially purified laccase enzyme [12].

\subsection{Data Analysis}

Graph-Pad Prism V 7.00 (San Diego, CA, USA) and Microsoft Excel (Redmond, WA, USA) computer programs were used for data analysis. All the values reported here in are average of triplicate measurements.

\section{Results}

\subsection{Isolation and Screening of Laccase-Producing Microbes}

Fifty-three microbial isolates were obtained from soil sample cultures. Among them, 30 were identified as Actinomycetes based on their morphological studies. They were named as CDBT-A-1 to 30, respectively. Twenty isolates were Streptomyces and were named as CDBT-S-1 to 20, respectively. Three were fungal isolates and named as CDBT-F-G1, G2, and G3, respectively. In the initial screening for laccase production, oxidation of guaiacol, tannic acid, and 1-naphthol were used and the plates were scored visually for laccase activity after five days of culture. The oxidative polymerization of guaiacol led to the formation of a reddish-brown zone, oxidation of tannic acid formed a brown color zone and oxidation of 1-naphthol formed a deep purple zone. Among the 53 isolates tested, 12 isolates tested positive for laccase activity in terms of guaiacol test, tannic acid test, or 1-naphthol. Among them, one tested positive, two were Actinomycetes, seven were Streptomycetes, and three were fungi (Table 1). The Streptomycetes isolate, viz., CDBT-S-16, and the fungal isolate, viz., CDBT-F-G1, appear 
to secrete highest levels of laccase (Figure 1). CDBT-F-G1 fungal isolate was tested several times to confirm the fact that it produces the highest level of laccase activity among all of the 53 isolates tested herein. All further studies described in this paper were performed using the CDBT-F-G1 fungal isolate.

Table 1. Screening of soil isolates for laccase activity *.

\begin{tabular}{cccccc}
\hline S.N. & Sample Code & Type of Species & Guaiacol & Tannic Acid & 1-Napthol \\
\hline 1 & CDBT-A-3 & Actinomycetes & + & ++ & $+/-$ \\
2 & CDBT-A-5 & Actinomycetes & + & ++ & $+/-$ \\
3 & CDBT-S-6 & Streptomycetes & + & ++ & $+/-$ \\
4 & CDBT-S-7 & Streptomycetes & + & ++ & $+/-$ \\
5 & CDBT-S-10 & Streptomycetes & + & ++ & $+/-$ \\
6 & CDBT-S-11 & Streptomycetes & + & ++ & $+/-$ \\
7 & CDBT-S-13 & Streptomycetes & +++ & + & $+/-$ \\
8 & CDBT-S-14 & Streptomycetes & + & ++ & $+/-$ \\
9 & CDBT-S-16 & Streptomycetes & ++ & +++ & $+/-$ \\
10 & CDBT-F-G1 & Fungi & +++++ & +++++ & $+/-$ \\
11 & CDBT-F-G2 & Fungi & + & + & $+/-$ \\
12 & CDBT-F-G3 & Fungi & + & + & + \\
\hline
\end{tabular}

* Screening for laccase activity was performed as described in materials and methods. Substrates used for screening were guaiacol $(0.02 \% w / w)$, tannic acid $(0.5 \% w / w)$ and 1-napthol $(5 \mathrm{mM})$; Scoring: $+/-=$ positive but barely visible; $+=$ pale to moderately pale color; $++=$ moderately pale to strong color; $+++=$ moderately strong to intense color; $>++++=$ strongly intense color.

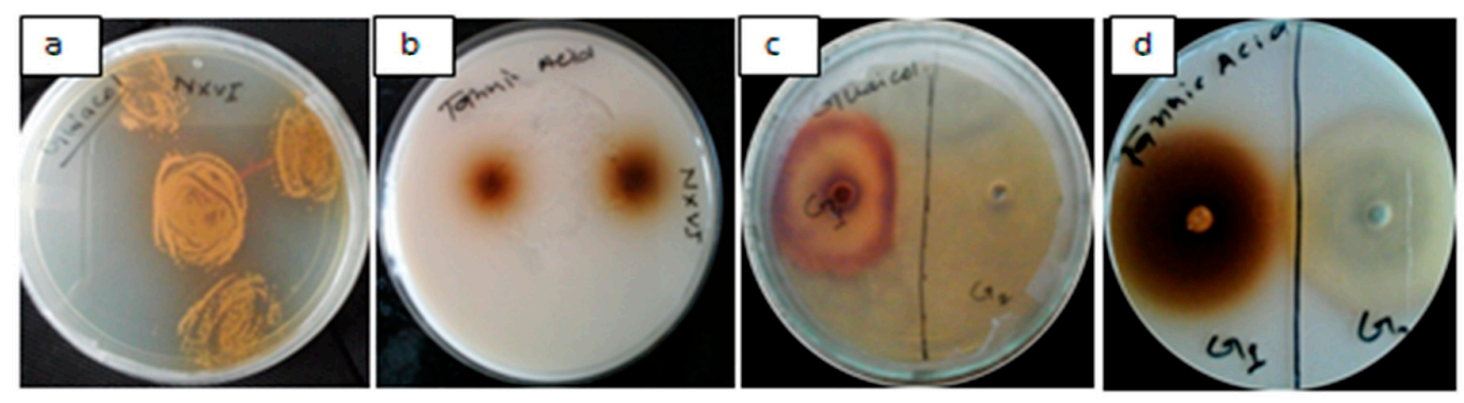

Figure 1. Screening of Streptomycetes isolate CDBT-S-16 and fungal isolates CDBT-F-G1 and G2 for secretion of laccase enzyme. (a) CDBT-S-16 stained with guaiacol; (b) CDBT-S-16 stained with tannic acid; (c) CDBT-F-G1 and CDBT-F-G2 stained with guaiacol, and (d) CDBT-F-G1 and CDBT-F-G2 stained with tannic acid.

\subsection{Morphology of CDBT-F-G1 Fungal Isolate}

The CDBT-F-G1 isolate was obtained from dry mushroom cut tissue and appears to be an endophyte. The CDBT-F-G1 isolate on potato dextrose broth forms white, cotton-like margins, are nearly round acervuli developed in mycelia, punctate, discrete, scattered, and irregular (Figure 2a). Microscopy of CDBT-F-G1 isolate by lactophenol cotton blue staining showed that the spores are four-to six-celled conidia with deeply olivaceous central cells, brown to black in color, with simple appendages arising from the apex (Figure 2b). 

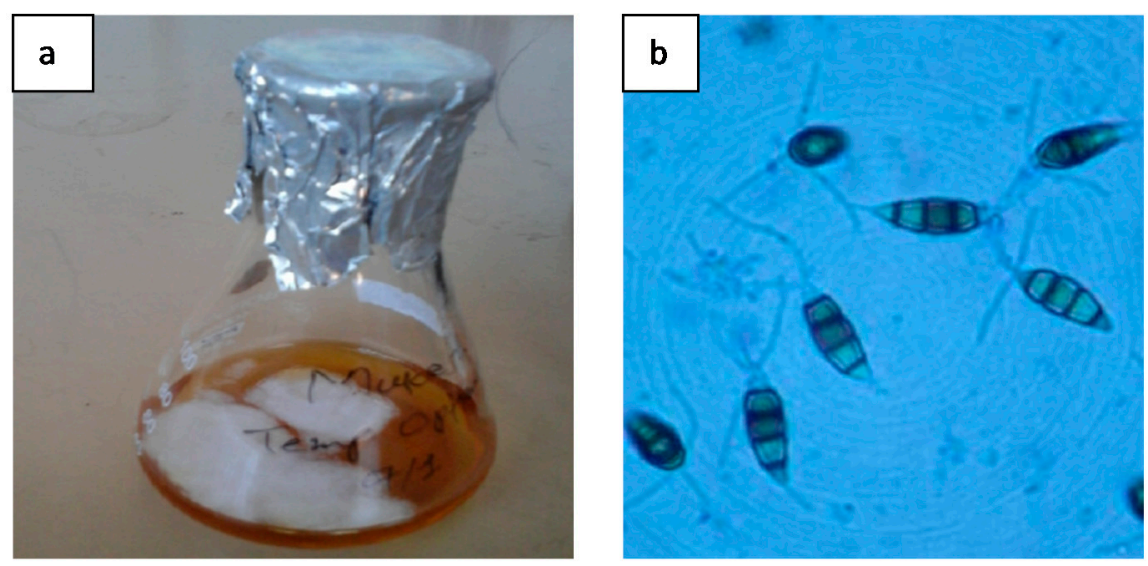

Figure 2. Morphological appearance of CDBT-F-G1 fungal isolate. Staining of CDBT-F-G1 isolate by lactophenol cotton blue was as described in the Section 2. (a) CDBT-F-G1 growing on PDB containing $1 \%$ Kraft lignin, and (b) appearance of CDBT-F-G1 conidia when stained with lactophenol cotton blue (magnification: $100 \times$ ).

\subsection{Extraction of gDNA from CDBT-F-G1 Isolate and PCR Amplification of 18s RNA Gene}

The genomic DNA extracted from CDBT-F-G1 was subjected to PCR amplification using 18s rRNA primer (Figure 3). The size of PCR product was found to be $658 \mathrm{bp}$. The PCR product was sequenced (Xcelris Labs Ltd., Ahmedabad, India) and the sequences were used in BLAST analysis to determine possible similarities and find the most probable genus of the CDBT-F-G1 fungal isolate.



Figure 3. Agarose gel-electrophoresis of PCR amplified 18s rRNA gene product. PCR amplification and agarose gel electrophoresis were as described in the Section 2. Lane 1: DNA markers (100 bp ladder from NEB Inc., Boston, MA, USA), Lane-2: PCR amplified 18s rRNA gene product.

Molecular Evolutionary Genetics Analysis (Mega 7) software was used to conduct sequence alignment. The aligned sequences with top-scores were used to develop phylogenetic tree. The analyses used to construct a phylogenetic tree used the following specifications: nucleotides were used as substitution types and maximum likelihood was used as the statistical method. Sequence similarity searches were performed for the fungal sequences against the non-redundant database maintained by the National Center for Biotechnology Information (NCBI) using the BLAST tool to infer functional 
and evolutionary relationships between sequences, and to help identify members of gene families. This analysis confirmed that CDBT-F-G1 isolate has maximum similarity with Pestalotiopsis spp. (Figure 4).

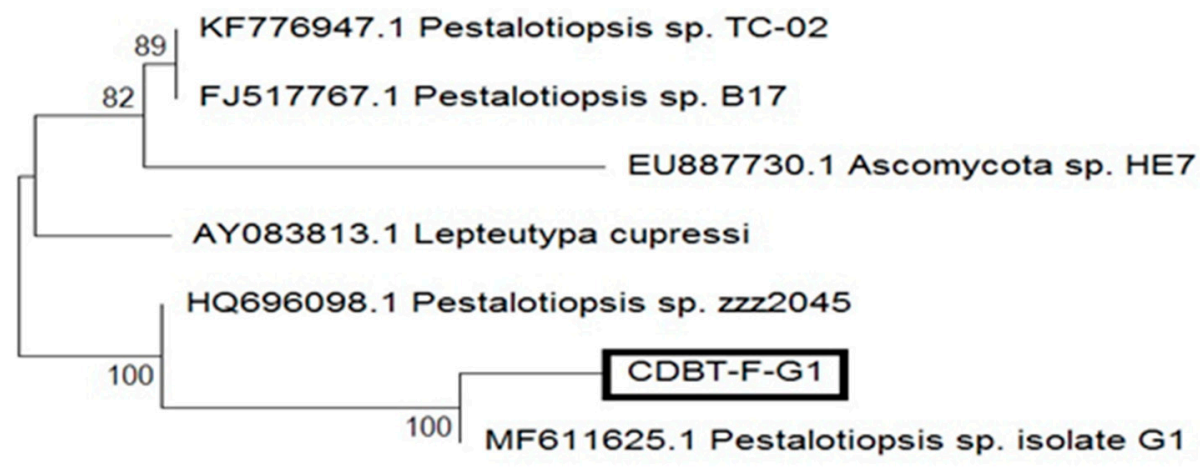

$$
0.0020
$$

Figure 4. Phylogenetic tree construct of Isolate CDBT-F-G1 using the maximum likelihood method.

Continuing with our quest to identify species expressing laccases to be used in commercial process for the pretreatment of lignocellulosic biomass, we have attempted to optimize and partially characterize the enzyme produced by Pestalotiopsis spp. CDBT-F-G1 fungal isolate and compared its properties to other laccases previously reported.

\subsection{Production Media Optimization for Laccase Production}

\subsubsection{Effect of $\mathrm{pH}$}

The effect of $\mathrm{pH}$ on the growth CDBT-F-G1 (Pestalotiopsis spp.) fungal isolate and its ability to secrete laccase was observed by varying the $\mathrm{pH}$ of the culture media between $\mathrm{pH} 4.0$ to 10.0 (Figure 5a). The CDBT-F-G1 isolate secreted the highest amounts of laccase when the culture media $\mathrm{pH}$ was 5.0 (20 $\pm 2 \mathrm{U} / \mathrm{mL}$ on day 9). The secretory enzyme levels decreased sharply in the culture medium as the $\mathrm{pH}$ of the culture medium increased from 5.0 to neutral range. Laccase levels further sharply decreased when the culture media was alkaline.

\subsubsection{Effect of Temperature}

The effect of temperature on secretion of laccase by CDBT-F-G1 was tested in the range of $20^{\circ} \mathrm{C}$ to $50{ }^{\circ} \mathrm{C}$ at intervals of $5^{\circ} \mathrm{C}$. Optimal temperature at which CDBT-F-G1 isolate secretes highest amounts of laccase $\left(23 \pm 0.4 \mathrm{U} / \mathrm{mL}\right.$ ) was found to be $30{ }^{\circ} \mathrm{C}$ (Figure $5 \mathrm{~b}$ ).

\subsubsection{Effects of Metal Ions on Laccase Production}

The effect of copper and other important metal ions on laccase secretion in Pestalotiopsis CDBT-F-G1 isolate was studied under optimized culture conditions (Figure 5c). All of the metal ions used were found to enhance laccase secretion. However, the maximum laccase activity (51 \pm $25 \mathrm{U} / \mathrm{mL}$ ) was obtained when the culture media was supplemented with $1 \mathrm{mM}$ magnesium sulfate in nine-day cultures. 

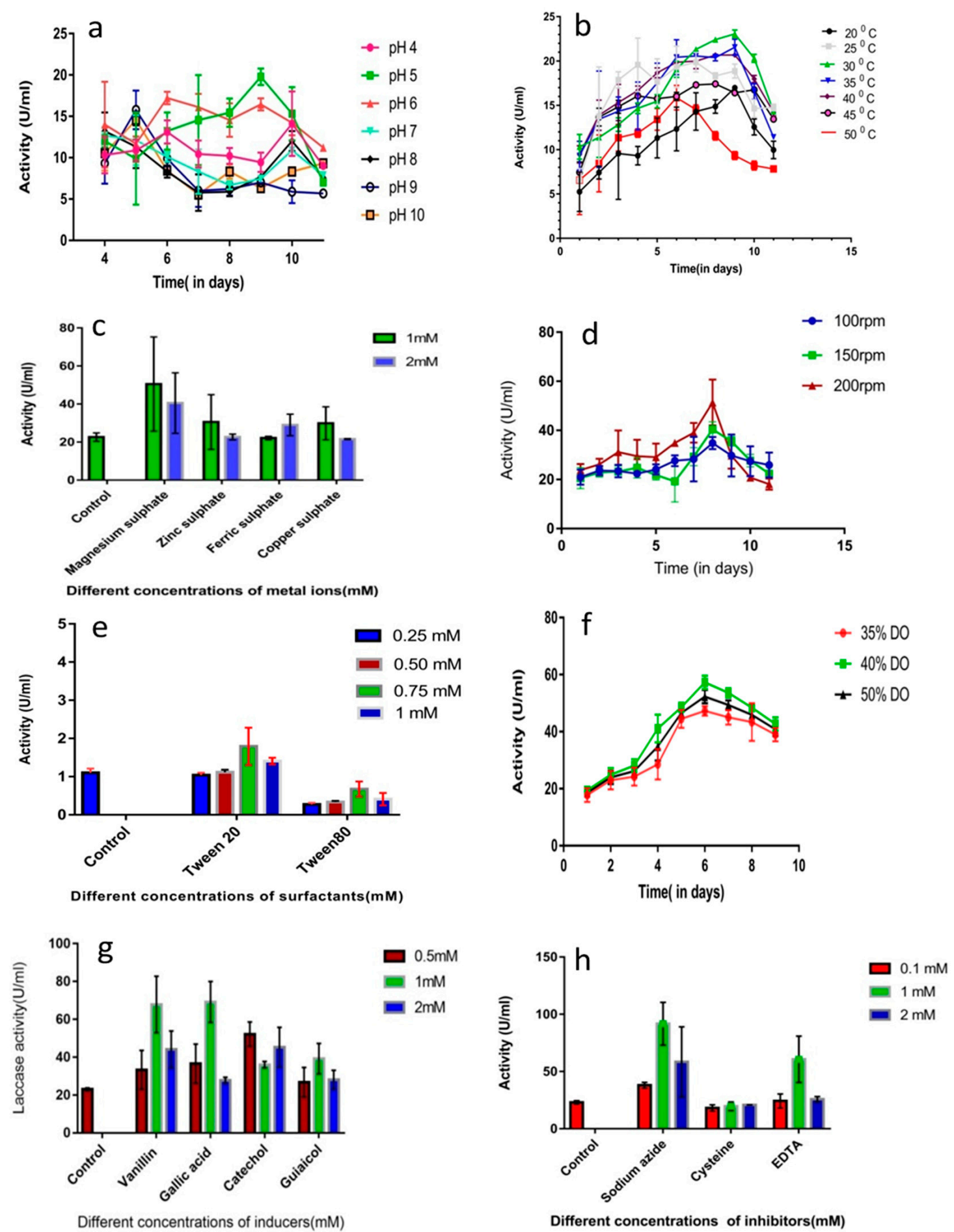

Figure 5. Optimization of culture media for the production of laccase in Pestalotiopsis CDBT-F-G1 cultures. Effect of (a) $\mathrm{pH},(\mathbf{b})$ temperature, (c) metal ions, (d) agitation, (e) surfactants aromatic substrate, (f) dissolved oxygen (DO), (g) inducers, and (h) inhibitors. Pestalotiopsis CDBT-F-G1 isolate was cultured in PDB medium ( $\mathrm{pH}$ ) supplemented with $1 \% \mathrm{Kraft}$ lignin at $30^{\circ} \mathrm{C}$. Enzyme activity was determined as described in Section 2.

\subsubsection{Effect of Agitation}

The agitation of fungal cultures is important not only for their growth but also for their ability to secrete enzymes. Pestalotiopsis CDBT-F-G1 isolate was optimized to secrete laccase by agitating the cultures at 100, 150, and $200 \mathrm{rpm}$, respectively. Laccase enzyme levels in the cultures were measured 
daily for up to11 days. Maximum level of laccase $(51 \pm 9 \mathrm{U} / \mathrm{mL})$ was found on the eighth day with an agitation rate of $200 \mathrm{rpm}$ (Figure 5d). It is observed that increased agitation aids in optimal secretion of laccase in a shorter time.

\subsubsection{Effects of Surfactant on Laccase Production}

In our study, the effect of surfactants, viz., Tween-20 and Tween-80, on the production of laccase by Pestalotiopsis CDBT-F-G1 isolate were studied at concentrations ranging from 0.25 to $1.0 \mathrm{mM}$. Supplementing the culture media with Tween- $80(0.75 \mathrm{mM})$ stimulated production of laccase $(54 \pm$ $14 \mathrm{U} / \mathrm{mL}$ ) (Figure 5e). At concentrations below or above $0.75 \mathrm{mM}$ Tween-80, the increments were modest. On the other hand, $0.75 \mathrm{mM}$ Tween-20 resulted in higher levels laccase in the culture media but it was less pronounced as compared to the effect of Tween-80.

\subsubsection{Effect of Dissolved Oxygen (DO)}

DO levels are also known to affect secretion of laccases. In our study, Pestalotiopsis CDBT-F-G1 isolate cultures were adjusted to $35 \%, 40 \%$, and $50 \%$, respectively, by supplying sterile air to observe the secretion of laccase. A $40 \%$ DO in the cultures was found to be best for secretion of laccase (57 $\pm 2 \mathrm{U} / \mathrm{mL}$ ) on the sixth day (Figure $5 \mathrm{f}$ ). After the sixth day, laccase activity gradually decreased in the cultures.

\subsubsection{Effects of Inducers and Inhibitors}

The effects of vanillin, guaiacol, catechol, gallic acid, sodium azide, cysteine, and EDTA were tested on Pestalotiopsis CDBT-F-G1 isolate at the concentrations of $0.5,1$, and $2 \mathrm{mM}$ in the culture medium (Figure $5 \mathrm{~g}, \mathrm{~h})$. Gallic acid $(1 \mathrm{mM})$ induced the highest levels of laccase $(69 \pm 11 \mathrm{U} / \mathrm{mL})$ and slightly less by $1 \mathrm{mM}$ vanillin $(68 \pm 15 \mathrm{U} / \mathrm{mL})$. Higher concentrations of vanillin or gallic acid had no further effect. Catechol, at the concentrations tested, induced modest amounts of laccase secretion. On the other hand, guaiacol had no effect on the induction of laccase. Cysteine modestly inhibited the secretion of laccase in Pestalotiopsis CDBT-F-G1 isolate cultures. EDTA, at $1 \mathrm{mM}$ concentrations promoted the modest secretion of laccase. At all concentrations tested, sodium azide induced the secretion of laccase in Pestalotiopsis CDBT-F-G1 isolate cultures.

\subsection{Partial Purification of Laccase from Fermentation Broth}

Pestalotiopsis CDBT-F-G1 isolate was cultured in a submerged bioreactor under optimized conditions as described in the Materials and Methods section. Supernatant of the culture medium was used for partial purification of laccase enzyme by ammonium sulfate and acetone precipitation techniques. The precipitate obtained from $100 \mathrm{~mL}$ of broth in between $40-70 \%$ ammonium sulfate was reconstituted in $10 \mathrm{~mL} 0.1 \mathrm{M}$ sodium acetate buffer $\mathrm{pH}$ 5.0. The reconstituted sample was first dialyzed against $0.1 \mathrm{M}$ sodium acetate, $\mathrm{pH} 5.0$, overnight at $4{ }^{\circ} \mathrm{C}$. The dialyzed sample was then used to determine laccase activity and protein concentration. The activity of laccase in the dialyzed sample was $882 \mathrm{U} / \mathrm{mL}$ and protein concentration was $33.6 \mu \mathrm{g} / \mathrm{mL}$. The specific activity of laccase was found to be $26,200 \mathrm{U} / \mathrm{mg}$ with $69 \%$ recovery of enzyme (Table 2 ). Acetone precipitation technique was also used to partially purify the enzyme. The protein precipitate obtained by the addition of five times the volume of cold acetone in $100 \mathrm{~mL}$ broth was reconstituted in $10 \mathrm{~mL}$ of $0.1 \mathrm{M}$ sodium acetate and dialyzed as above. The specific activity of laccase partially purified by acetone precipitation was found to be $31,700 \mathrm{U} / \mathrm{mg}$ (laccase activity: $957 \mathrm{U} / \mathrm{mL}$ and protein concentration: $30.1 \mu \mathrm{g} / \mathrm{mL}$ ). 
Table 2. Summary of partial purification of laccase from Pestalotiopsis CDBT-F-G1.

\begin{tabular}{cccccc}
\hline Fraction Analyzed & $\begin{array}{c}\text { Activity } \\
(\mathbf{U} / \mathbf{m L})\end{array}$ & $\begin{array}{c}\text { Protein } \\
(\boldsymbol{\mu g} / \mathbf{m L})\end{array}$ & $\begin{array}{c}\text { Specific Activity } \\
(\mathbf{U} / \mathbf{m g})\end{array}$ & $\begin{array}{c}\text { Fold } \\
\text { Purification }\end{array}$ & \% Recovery \\
\hline Culture media filtrate & 69.2 & 184 & 377 & 1.0 & 100 \\
\hline $\begin{array}{c}\text { Ammonium sulfate } \\
\text { fraction }(40-70 \%)\end{array}$ & 882 & 33.6 & 26,200 & 13 & 69 \\
\hline $\begin{array}{c}\text { Acetone precipitate } \\
(1: 5 \text { volume fraction) }\end{array}$ & 957 & 30.1 & 31,700 & 14 & 84 \\
\hline
\end{tabular}

\subsection{Characterization of Partially Purified Laccase}

\subsubsection{Temperature Optima and Thermal Stability}

The influence of temperature on Pestalotiopsis CDBT-F-G1 laccase was determined at temperatures ranging from $20^{\circ} \mathrm{C}$ to $80^{\circ} \mathrm{C}$ using ammonium sulfate faction. The optimal temperature for laccase was determined to be $60^{\circ} \mathrm{C}$ (Figure 6a). Enzyme activity decreased when the temperature was increased from $60^{\circ} \mathrm{C}$ to $80^{\circ} \mathrm{C}$. The stability of the enzyme with respect to temperature was also studied (Figure $6 \mathrm{~b}$ ). The enzyme is relatively stable between $30-50^{\circ} \mathrm{C}$ for up to $120 \mathrm{~min}$. The enzyme activity significantly drops within $30 \mathrm{~min}$ at temperature above $60^{\circ} \mathrm{C}$. Within $60 \mathrm{~min}$, laccase activity at $70{ }^{\circ} \mathrm{C}$ decreased by $36 \%$ of the initial activity, while after $180 \mathrm{~min}$ at $70{ }^{\circ} \mathrm{C}$ laccase activity decreased by $95 \%$.
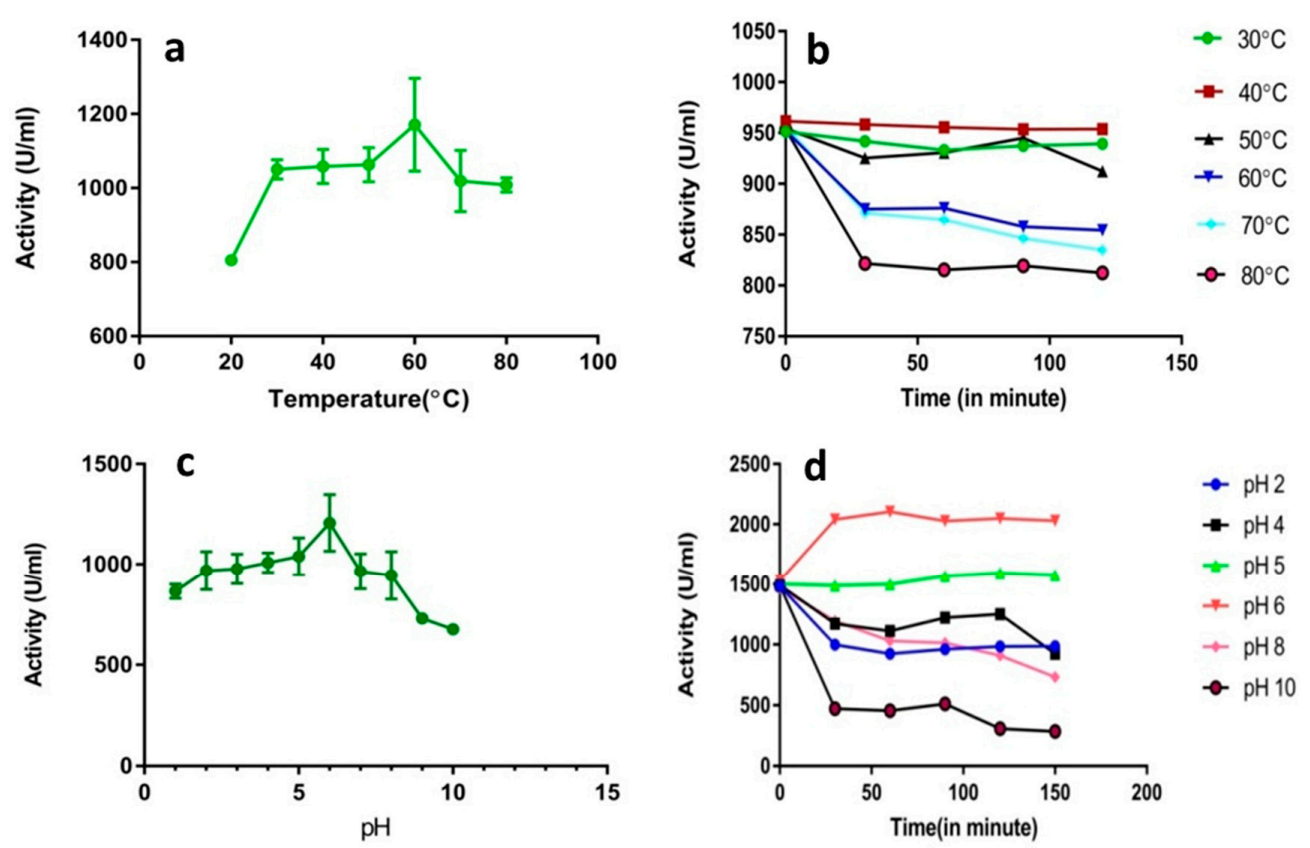

Figure 6. Temperature and $\mathrm{pH}$ optima and temperature and $\mathrm{pH}$ stability of partially purified laccase from Pestalotiopsis CDBT-F-G1. The experimental conditions were as described in Section 2. Experiments described in panel (a) (temperature optima) and panel (b) (temperature stability) were performed at pH 5 (0.1 M sodium acetate buffer, $\mathrm{pH}$ 5) and the experiments described in panel (c) (pH optima) and panel (d) ( $\mathrm{pH}$ stability) were performed at room temperature.

\subsubsection{Optimum $\mathrm{pH}$ and $\mathrm{pH}$ Stability}

The optimum $\mathrm{pH}$ for laccase isolated from Pestalotiopsis CDBT-F-G1 was observed at $\mathrm{pH} 6$ when ABTS was used as the substrate (Figure 6c). At $\mathrm{pH}$ values higher than $\mathrm{pH}$ 6, enzyme activity decreased gradually as compared to the activity observed at lower $\mathrm{pH}$. The enzyme was relatively stable at $\mathrm{pH} 5$ and 6 for up to $150 \mathrm{~min}$ (Figure $6 \mathrm{~d}$ ). 


\subsubsection{SDS-PAGE Analysis}

SDS-PAGE analysis of the partially purified protein factions showed the removal of most of contaminants and the laccase fraction contained a protein band in the region of $43 \mathrm{kDa}$ (Figure 7). Clearly, the precipitation techniques used herein result in the very high enrichment of laccase in the preparation (12.7-fold; Table 2).

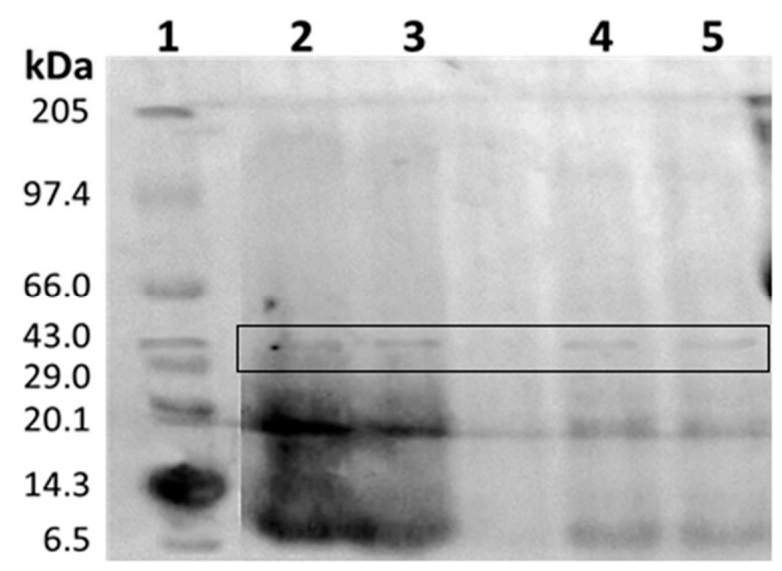

Figure 7. SDS-PAGE analysis various preparations of laccase enzyme. Lane 1: molecular mass markers; Lanes 2 and 3: CDBT-F-G1 culture broth, Lane 4: ammonium sulfate precipitate and Lane 5: acetone precipitate.

\subsubsection{Kinetic Constants}

The kinetic parameters $\left(\mathrm{K}_{\mathrm{m}}\right.$ and $\left.\mathrm{V}_{\max }\right)$ for the partially purified laccase from Pestalotiopsis CDBT-F-G1 strain were determined using ABTS as the substrate. The $K_{m}$ and $V_{\max }$ values derived from Lineweaver-Burk plot (Figure 8) for the partially purified laccase were $0.10 \mathrm{mM}$ and $100 \mu \mathrm{mol} / \mathrm{min}$, respectively.



Figure 8. Determination of kinetic constants for Pestalotiopsis CDBT-F-G1 laccase using ABTS as the substrate: Lineweaver-Burk plot. Enzyme activities were measured as described in Materials and Methods using varying concentrations of ABTS as the substrate. 


\section{Discussion}

In this study, out of 53 isolates, 12 were identified as laccase producers. Out of them, CDBT-F-G1 isolate was reported as potential laccase producer. This is the first report on isolation and characterization of laccase-producing strain from high altitudes of Nepal. Laccase secretion was monitored by visual color change in the plates. Reddish brown color with guaiacol and tannic acid, and a deep purple color with 1-naphthol, confirms laccase secretion $[17,18]$. Morphological and microscopic characteristics of CDBT-F-G1 were similar to the characteristics of Pestalotiopsis species as was described by Lazarotto and associates [19]. Isolate CDBT-F-G1 was an endophytic fungus with multi-septal spore morphology, with elongated flagella in spore cells (Figure 2b) [20]. According to Mycobank accession date 31 October, 2018, there are 334 associated records of Pestalotiopsis species. More recently, some new species have been added to the list based on host occurrence, and morphological and molecular data. They are mostly endophytic and to some extent, host-specific [13,15].

The optimum media $\mathrm{pH}$ for laccase secretion was different in various organisms and it was highly dependent on the substrate used. The observed optimum $\mathrm{pH}$ range of the culture media under which fungal species secrete laccases range from 3-7. This was consistent with the fact that Pestalotiopsis species are mesophilic fungi and mesophilic fungi, e.g., Ganoderma lucidum, have been reported to secrete highest levels of laccase at temperatures between $25-30{ }^{\circ} \mathrm{C}[18,21]$. Similarly, the isolate CDBT-F-G1 has highest laccase production at $\mathrm{pH} 5$ (Figure 5a) and a temperature optimum of $30^{\circ} \mathrm{C}$ (Figure 5b). Copper ions, as a micronutrient, play an important role as a metal activator. It induces both laccase transcription as well as plays an important role in laccase secretion [22]. Magnesium sulfate $(1 \mathrm{mM})$ was found to enhance laccase production in CDBT-F-G1 isolate (Figure 5c). These observations were consistent with literature reports wherein metal ions have been shown to enhance the growth of fungi, cause morphological and physiological changes, and affect the secretion of laccase [18,23]. Further, it has been observed that various strains and species of fungi differ in their sensitivity towards metals during their growth on lignocellulosic substrates [24]. Increased agitation was also found to increase laccase production in CDBT-F-G1 isolate (Figure $5 \mathrm{~d}$ ). The latter was probably due to proper mixing and easy access to nutrients. However, agitation as a factor that affects laccase production has been controversial. Tavares and associates have reported that agitation did not play any role in the production of laccase in Trametes versicolour cultures. The decrease in laccase production was believed to be due to mycelial damage caused by agitation, which, in turn, probably led to a considerable decrease in laccase production [25]. As compared to other Pestalotiopsis species, theCDBT-F-G1 strain reported herein was a better laccase producer, as well as a halotolerant fungus. Accordingly, we consider this as a novel fungus that is different from the other Pestalotiopsis species reported by Arfi and associates [26]. In yet another study, cultivation of white-rot fungus, viz., Bjerkandera adusta [27], in a stirred tank reactor, resulted in decreased levels of laccase activity. Again, this is also believed to be mycelial damage caused during agitation. Surfactants, especially Tween-80, increase the bioavailability of less soluble substrates for fungi and stimulate the growth of fungal spores as well as increase the production of metabolic enzymes, such as laccases, as shown inCDBT-F-G1 isolate (Figure 5e) [28]. The specific mechanism by which surfactants enhance extracellular enzyme production in fungi has not been elucidated in detail [29]. Increased secretion of laccase by fungi when cultured in media supplemented with aromatic compounds, such as vanillin, guaiacol, catechol, and gallic acid, has been well documented. The latter are considered as inducers for fungal enzymes, including laccase [30]. Similarly, the effect of sodium azide, cysteine, and EDTA have also been studied. Gallic acid, EDTA, and sodium azide (1 mM each) were found to increase laccase production in CDBT-F-G1 isolate (Figure 5h,g). However, Bollag and Leonowicz [31] have shown that azide, thioglycolic acid, and diethyldithiocarbamic acid inhibit secretion of laccase, whereas EDTA affected laccase secretion to a lesser extent. It is believed that small anions such as halides (excluding iodide), azide, cyanide, and hydroxide are known to bind to type- 2 and type- 3 copper, resulting in an interruption of internal electron transfer and thus inhibit laccase enzymes [32]. The inducing effect seen in our study may be due to increase in fungal biomass in the culture as azide ion mainly inhibits bacterial contamination in the culture. It has also been 
observed that promoter region encoding for laccases contains various recognition sites specific to xenobiotics. It is believed that aromatics, such as gallic acid, interact with the recognition sites and promote induction of laccase enzymes [33]. Further enhancement in laccase activity is possible by choosing suitable substrates. The Pestalotiopsis CDBT-F-G1 isolate reported herein shows two-fold higher levels of laccase secretion as compared to other Pestalotiopsis isolates ( $33 \pm 2 \mathrm{U} / \mathrm{mL})$ [34].

The specific activity of laccase was found to be $26,200 \mathrm{U} / \mathrm{mg}$ with $69 \%$ recovery of enzyme which is better than the laccase recovered by $60 \%$ and $80 \%$ ammonium sulfate $(65 \%$ and $63 \%)$ as reported by Rehman et al. and Vivekanandan et al. [35,36]. Further, acetone precipitated laccase resulted in better activity than ammonium sulfate precipitate (Table 2). In the latter study, it was reported that a high percentage of laccase retained in the protein precipitates of organic solvents, such as acetonitrile and acetone [37]. Although acetone precipitation provides better enrichment of laccase in the partially purified sample, economically, ammonium sulfate precipitation is more viable given the cost associated with precipitating agents. Accordingly, an ammonium sulfate fraction was used for further characterization of the laccase enzyme.

Laccase isolated, in this study, has an optimal $\mathrm{pH}$ and temperature of $\mathrm{pH} 6$ and $60{ }^{\circ} \mathrm{C}$ (Figure 6). The enzyme has a molecular mass of $43 \mathrm{kDa}$ (Figure 7). Similar enzymes have been reported previously from other Pestalotiopsis fungal species as well as Ganoderma lucidum CDBT 1 strain with $43 \mathrm{kDa}$ [18]. This enzyme isolated by precipitation techniques may be enough for the pretreatment of lignocellulosic biomass, however, additional methods of purification are necessary to obtain high-purity enzyme. It is important to note that laccase with a molar mass of $99 \mathrm{kDa}$ has also been reported in Pestalotiopsis species [38]. We do not see the $99 \mathrm{kDa}$ laccase protein in our preparations. The three possibilities as to why we did not see the second isozyme of laccase with $99 \mathrm{kDa}$ in our preparations include: (i) this isozyme was not secreted; (ii) expression of this isozyme was not induced; or (iii) its concentrations were below the detectable levels. Consistent with our observation, others have also observed a single isozyme of laccase secretion by fungi cultured in the presence of phenolic compounds [39]. The other protein bands observed in partially purified preparations were co-precipitating proteins and were unlikely to be laccases because most known laccases have molecular masses larger than $30 \mathrm{kDa}$. The kinetic constants obtained for Pestalotiopsis CDBT-F-G1 laccase described herein (Figure 8) was very efficient as compared to the values reported previously. The $\mathrm{K}_{\mathrm{m}}$ and $\mathrm{V}_{\max }$ of laccase from Mycena purpureofusca were $0.3 \mathrm{mM}$ and $65 \mu \mathrm{M} / \mathrm{min}$, respectively. The measure of $\mathrm{V}_{\max } / \mathrm{K}_{\mathrm{m}}$ shows the catalytic efficiency. The catalytic efficiency $\left(\mathrm{V}_{\max } / \mathrm{K}_{\mathrm{m}}\right)$ of CDBT-F-G1 laccase was $1 / \mathrm{min}$ where as that of Mycena purpureofusca was only $0.2 / \mathrm{min}$. [40]. The CDBT-F-G1 laccase, reported herein, can be a desirable enzyme for lignin degradation as well as other industrial applications.

\section{Conclusions}

Twelve (two Actinomycetes, seven Streptomycetes, and three fungi) of the 53 isolates tested positive for laccase secretion. Among the 12 isolates positive for laccase, CDBT-F-G1 isolate, from high altitudes (1600 to $2303 \mathrm{~m}$ above sea level) of Kathmandu Valley expressed the highest levels of laccase. Through morphology and 18s RNA sequencing, the isolate has been identified as a Pestalotiopsis species. The culture conditions (PDB supplemented with 1\% Kraft lignin) for the growth of Pestalotiopsis species CDBT-F-G1 have been established and conditions for the secretion of laccase into the growth medium have been optimized at $\mathrm{pH} 5$ and $30{ }^{\circ} \mathrm{C}$ with supplementation of inducers and metal ions. The Pestalotiopsis species reported here in appears to secrete a single laccase $(\sim 43 \mathrm{kDa})$ with very high specificity for ABTS as the substrate. Thus, Pestalotiopsis species CDBT-F-G1 maybe a novel isolate for industrial laccase production.

Author Contributions: G.B., R.M., P.P., and M.M. were involved in the study design. M.Y. and J.J. carried out the experiments and wrote the initial manuscript. L.S. provided the ideas, helped with the experimental design, and edited the manuscript. All authors read and approved the final manuscript. 
Acknowledgments: Central Department of Biotechnology, Tribhuvan University is highly acknowledged for providing stock isolates, laboratory space and necessary facilities. Authors kindly acknowledge the Nepal Academy of Science and Technology for providing mushroom cultures.

Conflicts of Interest: There is no conflict of interest. The samples were soil and dry mushrooms and do not require any ethical consent.

\section{References}

1. Baldrian, P. Fungal laccases-occurrence and properties. FEMS Microbiol. Rev. 2016, 30, 215-242. [CrossRef]

2. Wesenberg, D.; Kyriakides, I.; Agathos, S.N. White-rot fungi and their enzymes for the treatment of industrial dye effluents. Biotechnol. Adv. 2003, 22, 161-187. [CrossRef]

3. Bourbonnais, R.; Paice, M.; Reid, I.; Lanthier, P.; Yaguchi, M. Lignin oxidation by laccase isozymes from Trametes versicolor and role of the mediator 2,2'-azinobis (3-ethylbenzthiazoline-6-sulfonate) in kraft lignin depolymerization. Appl. Environ. Microbiol. 1995, 61, 1876-1880.

4. Sharma, A.; Aggarwal, N.; Yadav, A. Isolation and Screening of Lignolytic Fungi from Various Ecological Niches. Univ. J. Microbiol. Res. 2017, 5, 25-34.

5. Robinson, T.; Chandran, B.; Nigam, P. Studies on the production of enzymes by white-rot fungi for the decolourisation of textile dyes. Enzym. Microb. Technol. 2001, 29, 575-579. [CrossRef]

6. Subramanian, J.; Ramesh, T.; Kalaiselvam, M. Fungal Laccases-Properties and Applications: A Review. Int. J. Pharm. Boil. Arch. 2014, 5, 8-16.

7. Verma, S.R.; Dwivedi, U.N. Lignin genetic engineering for improvement of wood quality: Applications in paper and textile industries, fodder and bioenergy production. S. Afr. J. Bot. 2014, 91, 107-125.

8. Williams, S.T.; Davies, F.L. Use of antibiotics for selective isolation and enumeration of Actinomycetes in soil. J. Gen. Microbiol. 1965, 38, 251-261. [CrossRef]

9. Aljanabi, S.M.; Martinez, I. Universal and rapid salt-extraction of high quality genomic DNA for PCR-based techniques. Nucleic Acids Res. 1997, 25, 4692-4693. [CrossRef]

10. Rajesh, K.; Dhanasekaran, D.; Panneerselvam, A. Isolation and taxonomic characterization of medicinal mushroom Ganoderma spp. Acad. J. Microbiol. Res. 2014, 2, 61-70.

11. More, S.S.; P.S., R.; K., P.; Malini, S.; S.M., V. Isolation, Purification, and Characterization of Fungal Laccase from Pleurotus sp. Enzyme Res. 2011, 2011, 248735.

12. Li, A.; Zhu, Y.; Xu, L.; Zhu, W.; Tian, X. Comparative study on the determination of assay for laccase of Trametes sp. Afr. J. Biochem. Res. 2008, 2, 181-183.

13. Han, M.J.; Han, M.; Choi, H.; Song, H. Purification and characterization of laccase from the white rot fungus Trametes versicolor. J. Microbiol. 2006, 43, 555-560.

14. Bryjak, J.; Rekuć, A. Effective purification of Cerrena unicolor laccase using microfiltration, ultrafiltration and acetone precipitation. Appl. Biochem. Biotechnol. 2010, 160, 2219-2235. [CrossRef] [PubMed]

15. Bradford, M.M. A rapid and sensitive method for the quantitation of microgram quantities of protein utilizing the principle of protein-dye binding. Anal. Biochem. 1976, 72, 248-254. [CrossRef]

16. Hildén, K.; Hakala, T.; Maijala, P.; Lundell, T.; Hatakka, A. Novel thermotolerant laccases produced by the white-rot fungus Physisporinus rivulosa. Appl. Microbiol. Biotechnol. 2007, 7, 301-309. [CrossRef] [PubMed]

17. Kiiskinen, L.L.; Ratto, M.; Kruus, K. Screening for novel laccase-producing microbes. J. Appl. Microbiol. 2004, 97, 640-646. [CrossRef] [PubMed]

18. Shrestha, P.; Joshi, B.; Joshi, J.; Malla, R.; Sreerama, L. Isolation and Physicochemical Characterization of Laccase from Ganoderma lucidum-CDBT1 Isolated from Its Native Habitat in Nepal. BioMed Res. Int. 2016, 2016, 3238909. [CrossRef]

19. Lazarotto, M.; Bovolini, M.P.; Muniz, M.F.B.; Harakawa, R.; Reiniger, L.R.S.; Santos, Á.F. Identification and characterization of pathogenic Pestalotiopsis species to pecan tree in Brazil. Pesq. Agropec. Brasil. 2014, 49, 440-448. [CrossRef]

20. Aly, A.H.; Debbab, A.; Kjer, J.; Proksch, P. Fungal endophytes from higher plants: A prolific source of phytochemicals and other bioactive natural products. Fungal Divers. 2010, 41, 1-16. [CrossRef]

21. Ko, E.M.; Leem, Y.E.; Choi, H.T. Purification and characterization of laccase isozymes from the white-rot basidiomycete Ganoderma lucidum. Appl. Microbiol. Biotechnol. 2001, 57, 98-102. [PubMed] 
22. Palmieri, G.; Giardina, P.; Bianco, C.; Fontanella, B.; Sannia, G. Copper induction of laccase isoenzymes in the ligninolytic fungus Pleurotus ostreatus. Appl. Environ. Microbiol. 2000, 66, 920-924. [CrossRef] [PubMed]

23. Wuyep, P.A.; Khan, A.U.; Nok, A.J. Production and regulation of lignin degrading enzymes from Lentinus squarrosulus (mont.) Singer and Psathyrella atroumbonata Pegler. Afr. J. Biotechnol. 2003, 2, 444-447.

24. Sathiya, M.; Periyar, S.; Sasikalaveni, A.; Murugesan, K.; Kalaichelvan, P.T. Decolorization of textile dyes and their effluents using white rot fungi. Afr. J. Biotechnol. 2007, 6, 424-429.

25. Tavares, A.P.M.; Coelho, M.A.Z.; Coutinho, J.A.P.; Xavier, A.M.R.B. Laccase improvement in submerged cultivation: Induced production and kinetic modelling. J. Chem. Technol. Biotechnol. 2005, 80, 669-676. [CrossRef]

26. Arfi, Y.; Chevret, D.; Henrissat, B.; Berrin, J.G.; Levasseur, A.; Record, E. Characterization of salt-adapted secreted lignocellulolytic enzymes from the mangrove fungus Pestalotiopsis sp. Nat. Commun. 2013, 4, 1810. [CrossRef]

27. Martina, M.; Jožefa, F.; Aleksander, P. Decoloration of the diazo dye reactive black by immolized Bjerkandera adusta in a stirred tank bioreactor. Acta Chim. Slov. 2004, 51, 619-628.

28. Zheng, Z.; Obbard, J.P. Oxidation of polycyclic aromatic hydrocarbons by fungal isolates from an oil contaminated refinery soil. Environ. Sci. Pollut. Res. 2003, 10, 173-176. [CrossRef]

29. Wong, D.W. Structure and Action Mechanism of Ligninolytic Enzymes. Appl. Biochem. Biotechnol. 2008, 157, 174-209. [CrossRef] [PubMed]

30. Ikehata, K.; El-Din, M.G. Degradation of Recalcitrant Surfactants in Wastewater by Ozonation and Advanced Oxidation Processes: A Review. Ozone Sci. Eng. 2004, 26, 327-343. [CrossRef]

31. Bollag, J.M.; Leonowicz, A. Comparative studies of extracellular fungal laccases. Appl. Environ. Microbiol. 1984, 48, 849-854. [PubMed]

32. Nadeem, A.; Baig, S.; Sheikh, N. Mycotechnological production of laccase by Pleurotus ostreatus-P1 and its inhibition study. J. Anim. Plant Sci. 2014, 24, 492-502.

33. Faraco, V.; Giardina, P.; Palmieri, G.; Sannia, G. Metal-activated laccase promoters. Prog. Biotechnol. 2002, 21, 105-111.

34. Hao, J.; Song, F.; Huang, F.; Yang, C.; Zhang, Z.; Zheng, Y.; Tian, X. Production of laccase by a newly isolated deuteromycete fungus Pestalotiopsis sp. and its decolorization of azo dye. J. Ind. Microbiol. Biotechnol. 2007, 34, 233-240.

35. Rehman, A.U.; Thurston, C.F. Purification of laccase I from Armillaria mellea. J. Gen. Microbiol. 1992, 138, 1251-1257. [CrossRef]

36. Vivekanandan, K.E.; Sivaraj, S.; Kumaresan, S. Characterization and purification of laccase enzyme from Aspergillus nidulans CASVK3 from vellar estuary south east coast of India. Int. J. Curr. Microbiol. App. Sci. 2014, 3, 213-227.

37. Marques De Souza, C.G.; Peralta, R.M. Purification and characterization of the main laccase produced by the white-rot fungus Pleurotus pulmonarius on wheat bran solid state medium. J. Basic Microbiol. 2003, 43, 278-286.

38. Rastogi, A.; Singh, P. Partial Purification and Characterization of Laccase Enzyme Isolated From Carpet and Textile Effluent. IOSR J. Biotechnol. Biochem. 2017, 3, 43-51.

39. Tapia-Tussell, R.; Pérez-Brito, D.; Torres-Calzada, C.; Cortés-Velázque, A.; Alzate-Gaviria, L.; Chablé-Villacís, R.; Solís-Pereira, S. Laccase Gene Expression and Vinasse Biodegradation by Trametes hirsuta Strain Bm-2. Molecules 2015, 20, 15147-15157. [CrossRef]

40. Sun, S.J.; Zhang, Y.H.; Que, Y.X.; Liu, B.X.; Hu, K.H.; Xu, L.P. Purification and Characterization of Fungal Laccase from Mycena purpureofusca. Chiang Mai J. Sci. 2013, 40, 151-160.

(C) 2019 by the authors. Licensee MDPI, Basel, Switzerland. This article is an open access article distributed under the terms and conditions of the Creative Commons Attribution (CC BY) license (http:/ / creativecommons.org/licenses/by/4.0/). 